\title{
Torque Ripples Minimization in DTC based Induction Motor Drive using Fuzzy Logic Technique
}

\author{
Allirani S \\ Sri Ramakrishna Engineering College, \\ Coimbatore-641 022, India
}

\author{
Jagannathan $\mathrm{V}$ \\ Coimbatore Institute of Technology, \\ Coimbatore-641 014, India
}

\begin{abstract}
This paper presents the application of fuzzy logic technique to reduce torque ripples in an induction motor drive employing direct torque control (DTC). The DTC is characterized by the absence of PI regulators, coordinate transformations, current regulators and PWM signals. The main drawback of DTC is its high torque ripples. In this proposed technique, the two hysteresis controllers are replaced by fuzzy logic controllers (FLC 1 and FLC 2). The distortions in flux, current and torque can be easily reduced by applying the selected inverter voltage vector only for the part and not for the entire switching period unlike in conventional DTC. The performance of the proposed system is evaluated through digital simulation using MATLAB - SIMULINK package. The simulation results verify the superiority of the proposed technique to the conventional DTC technique.
\end{abstract}

\section{Keywords}

Direct torque control, fuzzy logic controller, space vector modulation, induction motor drive, switching table.

\section{INTRODUCTION}

Advanced control of electrical machines requires an independent control of magnetic flux and torque. In early days $\mathrm{dc}$ machine played an important role since the magnetic flux and torque are easily controlled independently by the stator and rotor currents respectively. The introduction of field oriented control (FOC) in 1970s made huge turn in the control of induction motor drive. FOC uses frame transformation to decouple the torque and flux components of the stator current [1]. Therefore the performance of IM becomes similar to that of the dc motor. The implementation of this system however is complicated and is well known to be highly sensitive to parameter variations due to the feed forward structure of its control system [2]. Later in the eighties a new control technique named Direct Torque Control is introduced [3], [4]. The DTC is characterized by its simple structure and fast dynamic response. Also the inverter is directly controlled by the algorithm, i.e. a modulation technique for inverter is not needed. The main advantages of DTC are absence of coordinate transformation and current regulator, absence of separate voltage modulation block [5]. Common disadvantages of conventional DTC are sluggish response in both starts up and load changes [6]. Recent advancements in
DTC systems include the use of unified flux control scheme [7], stator flux vector control in field weakening region [8], intelligent techniques [9]-[11], torque ripple minimization techniques [12], space vector modulation (SVM) technique [13], SVM with adoptive stator flux observer [14], Field Programmable Gate Array (FPGA) [15].

In the conventional DTC, hysteresis controllers are a two value bang bang controllers, which has the same outputs for both small and big torque errors. Therefore torque ripples are produced. The torque ripples can be minimized by dividing the torque errors into several intervals on which control action taken. In this paper fuzzy logic based direct torque control is proposed. Here two fuzzy logic controllers for both flux and torque are proposed along with space vector modulation. The fuzzy controllers allow faster response and SVM technique provide a constant inverter switching frequency so small torque ripples and current distortion.

The proposed technique is simulated in MATLABSIMULINK package to validate the performance of the algorithm.

\section{PRINCIPLES OF DTC}

DTC provides very quick response with simple control structure and hence this technique is gaining popularity in industries [16]. In DTC, stator flux and torque are directly controlled by selecting the appropriate inverter state. The stator currents and voltages are indirectly controlled hence no current feedback loops are required. Nearly sinusoidal stator fluxes and stator currents enable high dynamic performance even at standstill [5].

The generic DTC scheme for a Voltage source PWM inverterfed IM drive is shown in Fig.1. The scheme includes two hysteresis controllers. The stator flux controller imposes the time duration of the active voltage vectors, which move the stator flux along the reference trajectory, and the torque controller determinates the time duration of the zero voltage vectors which keep the motor torque in the predefined hysteresis tolerance band. At every sampling time the voltage vector selection block chooses the inverter switching state $\left(\mathrm{S}_{\mathrm{A}}\right.$, $\mathrm{S}_{\mathrm{B}}, \mathrm{S}_{\mathrm{C}}$ ) which reduces the instantaneous flux and torque errors. 


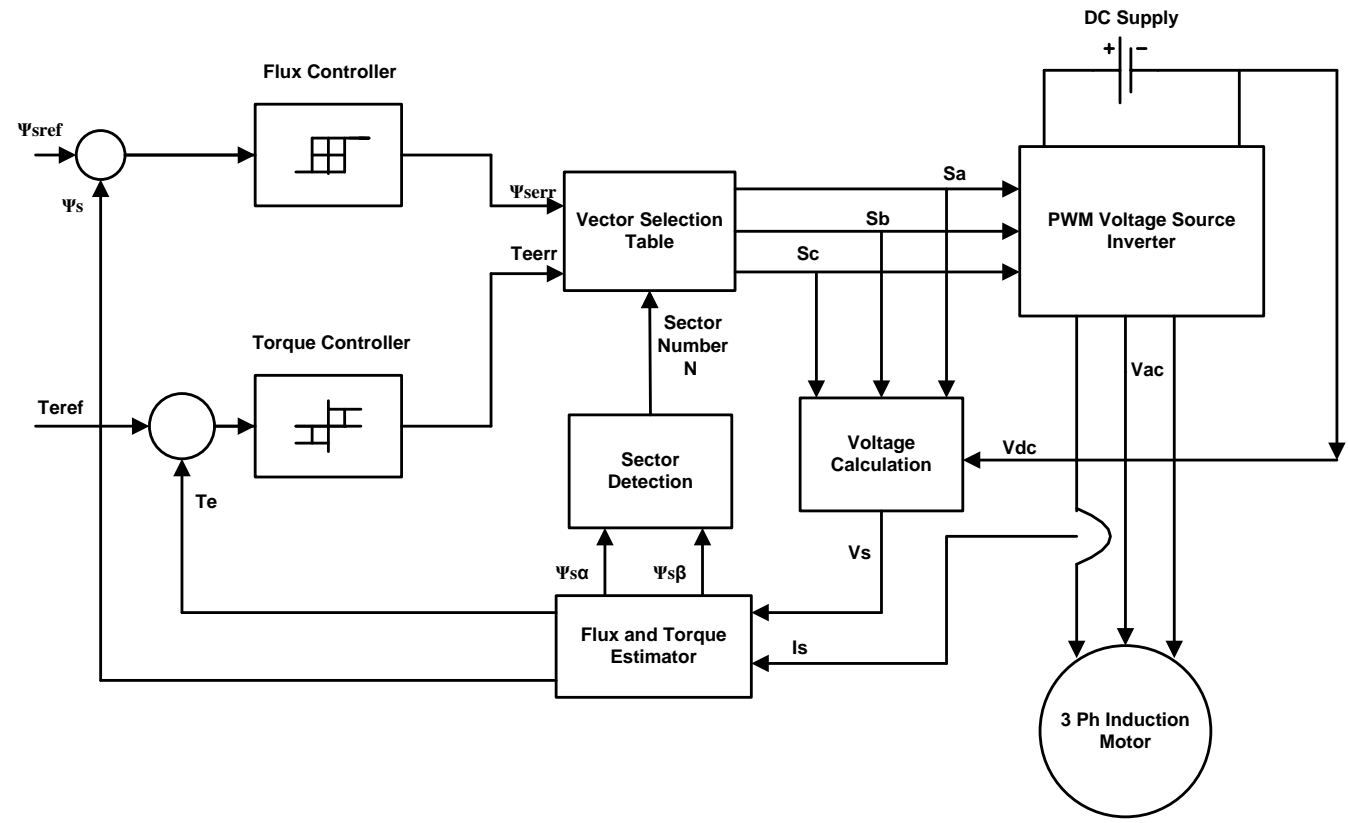

Figure 1 Basic scheme of PWM inverter fed induction motor with DTC

\section{BASIC SWITCHING TABLE AND SELECTION OF VOLTAGE VECTORS}

The basic idea of the switching table DTC concept is shown in Fig. 1. The command stator flux $\Psi_{\text {sref }}$, and torque $T_{\text {eref }}$ values are compared with the actual $\Psi_{s}$ and $T_{e}$ values in hysteresis flux and torque controllers, respectively. The flux controller is a two-level comparator while the torque controller is a three level comparator. The digitized output signals of the flux controller are defined as in equations (1) and (2)

$\psi_{\text {serr }}=1$, for $\psi_{s}<\psi_{\text {sref }}-H_{\psi}$

$\psi_{\text {serr }}=-1$, for $\psi_{s}<\psi_{\text {sref }}+H_{\psi}$

And those of the torque controller as in equations (3), (4), (5),

$$
\begin{aligned}
& T_{\text {eerr }}=1, \text { for } T_{e}<T_{\text {eref }}-H_{\psi} \\
& T_{\text {eerr }}=0, \text { for } T_{e}=T_{\text {eref }} \\
& T_{\text {eerr }}=-1, \text { for } T_{e}<T_{\text {eref }}+H_{\psi}
\end{aligned}
$$

where $2 H_{\Psi}$ is the flux tolerance band and $2 H_{m}$ is the torque tolerance band.

The digitized variables $\Psi_{\text {serr }}, T_{\text {eerr }}$ and the stator flux section (sector) $N$, obtained from the angular position given in equation (6)

$\alpha=\operatorname{arctg}\left(\Psi_{\mathrm{s} \beta} / \Psi_{\mathrm{s} \alpha}\right)$

create a digital word where,

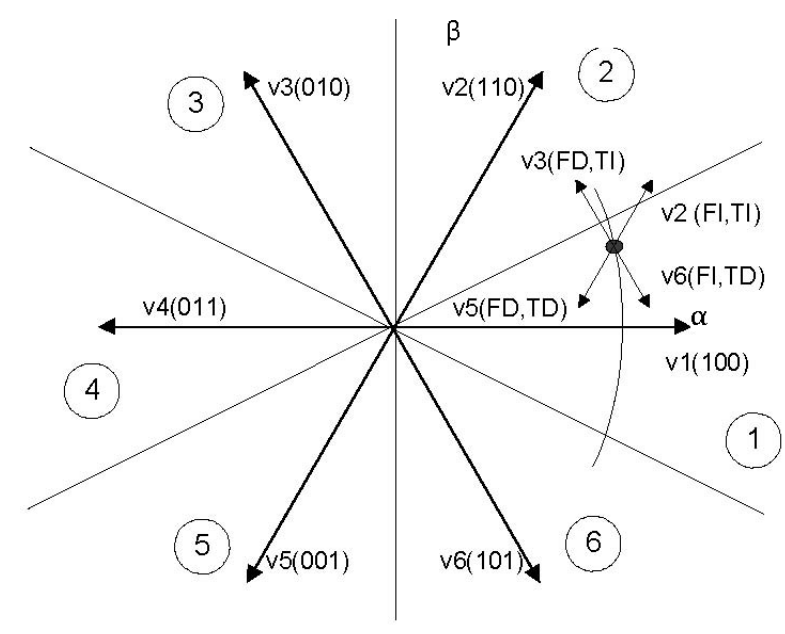

Figure 2 Inverter voltage vectors and stator flux switching sector

$$
\begin{aligned}
0^{\circ} & <\alpha(1)<30^{\circ} \\
30^{\circ} & <\alpha(2)<90^{\circ} \\
90^{\circ} & <\alpha(3)<150^{\circ} \\
150^{\circ}<\alpha(4) & <210^{\circ} \\
210^{\circ} & <\alpha(5)<270^{\circ} \\
270^{\circ}<\alpha(6) & <330^{\circ}
\end{aligned}
$$

On the basis of torque and flux hysteresis status and the stator flux switching sector, which is denoted by $\alpha$, DTC algorithm selects the inverter voltage vector from the Table I. The outputs of the switching table are the settings for the switching devices of the inverter. Fig. 2 shows the relation of inverter voltage vector and stator flux switching sectors. Six 
active switching vectors $\mathrm{V} 1, \mathrm{~V} 2, \mathrm{~V} 3, \mathrm{~V} 4, \mathrm{~V} 5, \mathrm{~V} 6$ and two zero switching vectors $\mathrm{V} 0$ and $\mathrm{V} 7$ determine the switching sequence of the inverter. Depending on inverter switching pulses, PWM is achieved and hence stator voltages and currents are controlled [3]. Therefore to obtain a good dynamic performance, an appropriate inverter voltage vectors $V_{i}(i=1$ to 6$)$ have to be selected.

Table 1 Switching table of Inverter Voltage Vectors

\begin{tabular}{|c|c|c|c|c|c|c|c|}
\hline \multirow{2}{*}{$\Psi_{\text {serr }}$} & $\mathrm{T}_{\text {eerr }}$ & $\begin{array}{c}\alpha(1) \\
\text { sect1 }\end{array}$ & $\begin{array}{c}\alpha(2) \\
\text { sect2 }\end{array}$ & $\begin{array}{c}\alpha(3) \\
\text { sect3 }\end{array}$ & $\begin{array}{c}\alpha(4) \\
\text { sect4 }\end{array}$ & $\begin{array}{c}\alpha(5) \\
\text { sect5 }\end{array}$ & $\begin{array}{c}\alpha(6) \\
\text { sect 6 }\end{array}$ \\
\hline \multirow{3}{*}{1} & 1 & $\mathrm{~V} 2$ & $\mathrm{~V} 3$ & $\mathrm{~V} 4$ & $\mathrm{~V} 5$ & $\mathrm{~V} 6$ & $\mathrm{~V} 1$ \\
\cline { 2 - 8 } & 0 & $\mathrm{~V} 7$ & $\mathrm{~V} 0$ & $\mathrm{~V} 7$ & $\mathrm{~V} 0$ & $\mathrm{~V} 7$ & $\mathrm{~V} 0$ \\
\cline { 2 - 8 } & -1 & $\mathrm{~V} 6$ & $\mathrm{~V} 1$ & $\mathrm{~V} 2$ & $\mathrm{~V} 3$ & $\mathrm{~V} 4$ & $\mathrm{~V} 5$ \\
\hline \multirow{3}{*}{0} & 1 & $\mathrm{~V} 3$ & $\mathrm{~V} 4$ & $\mathrm{~V} 5$ & $\mathrm{~V} 6$ & $\mathrm{~V} 1$ & $\mathrm{~V} 2$ \\
\cline { 2 - 8 } & 0 & $\mathrm{~V} 0$ & $\mathrm{~V} 7$ & $\mathrm{~V} 0$ & $\mathrm{~V} 7$ & $\mathrm{~V} 0$ & $\mathrm{~V} 7$ \\
\cline { 2 - 8 } & -1 & $\mathrm{~V} 5$ & $\mathrm{~V} 6$ & $\mathrm{~V} 1$ & $\mathrm{~V} 2$ & $\mathrm{~V} 3$ & $\mathrm{~V} 4$ \\
\hline
\end{tabular}

\subsection{Stator Flux Control}

By selecting the appropriate inverter output voltage $\mathrm{V}_{\mathrm{i}}(\mathrm{i}=1-6)$, the stator flux $\Psi_{s}$ rotates at the desired frequency $\omega_{s}$ inside a specified band. If the stator ohmic drops are neglected, the stator voltage impresses directly the stator flux in accordance with the equations (7) and (8).

$V_{s}=\frac{d \psi_{s}}{d t}$

$d \psi_{s}=V_{s} d t$

Therefore the variation of the stator flux space vector due to the application of the stator voltage vector $\mathrm{V}_{\mathrm{s}}$ during a time interval of $\Delta t$ can be approximated as in equation (9).

$$
\Delta \psi_{s}=V_{s} \Delta t
$$

\subsection{Torque Control}

$$
T_{e}=\frac{3}{2} \frac{P}{2} \frac{L_{m}}{L_{s}^{\prime}} \psi_{s} \psi_{r} \sin \gamma
$$

The electromagnetic torque given by equation (10) is a sinusoidal function of $\gamma$, the angle between $\Psi_{S}$ and $\Psi_{r}$ as shown in Fig.3. The variation of stator flux vector will produce a variation in the developed torque because of the variation of the angle $\gamma$ between the two vectors as in equation (11).

$$
\Delta T_{e}=\frac{3}{2} \frac{P}{2} \frac{L_{m}}{L_{s}^{\prime}}\left(\psi_{s}+\Lambda \psi_{s}\right) \psi_{r} \sin \Delta \gamma
$$

In accordance with the Fig. 1, the flux linkage and torque errors are restricted within its respective hysteresis bands. It can be proved that the flux hysteresis band affects the statorcurrent distortion in terms of low order harmonics and the torque hysteresis band affects the switching frequency. The DTC requires the flux and torque estimations, which can be performed as proposed in this model, by means of two different phase currents and the state of the inverter. The flux and torque estimations can be performed by means of other estimators using other magnitudes such as two stator currents and the mechanical speed, or two stator currents again and the shaft position [3].

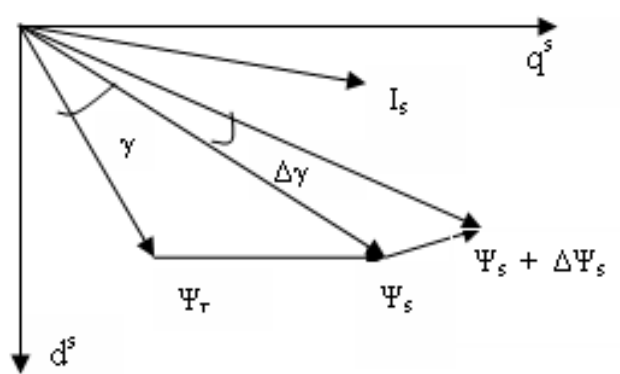

Figure 3 Stator flux and rotor flux space vectors

\section{FUZZY LOGIC BASED DTC}

Fig. 4 shows the schematic of proposed SVM based DTC with fuzzy controllers. Two mamdani type fuzzy logic controllers (FLC - 1 \& FLC - 2) which contain fuzzifier, inference engine, rule base and defuzzifier replace the two hysteresis comparators in conventional DTC.

\subsection{Flux error fuzzification}

The flux error is obtained from equation (12)

$\Delta \Psi=\Psi_{\mathrm{s}}^{*}-\Psi_{\mathrm{s}}$

For flux error, there are three linguistic terms negative error, zero error and positive error denoted as $\mathrm{N}, \mathrm{Z}$ and $\mathrm{P}$. 


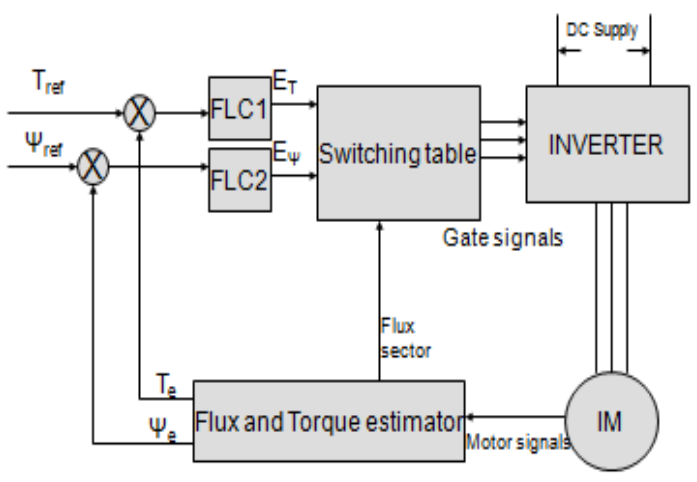

Figure 4 SVM based DTC with fuzzy controllers

Three fuzzy sets are then defined by the triangular membership functions given in fig. 5 .

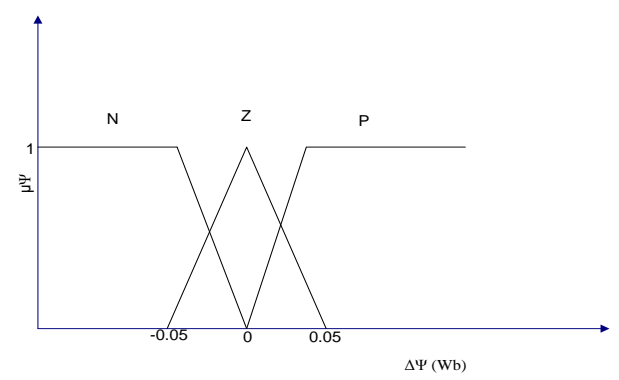

Figure 5 Fuzzy membership function for Flux error fuzzification

\subsection{Electromagnetic torque error fuzzification}

Torque error is obtained from the reference electromagnetic torque and estimated electromagnetic torque as in equation (13).

$\Delta \mathrm{T}_{\mathrm{e}}=\mathrm{T}_{\mathrm{e}}^{*}-\mathrm{T}_{\mathrm{e}}$

The linguistic variables are negative value, zero value and positive value denoted as NE, ZE and PE. The membership functions for torque error are shown in fig. 6

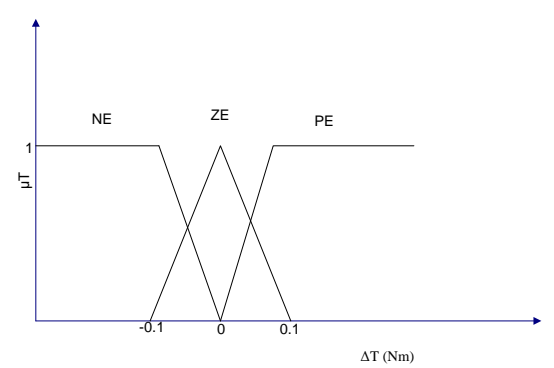

Figure 6 Fuzzy membership function for torque error fuzzification

\section{SIMULATION RESULTS}

To study the performance of the proposed SVM based DTC with fuzzy logic controllers, simulation was carried out using MATLAB/SIMULINK simulation package.

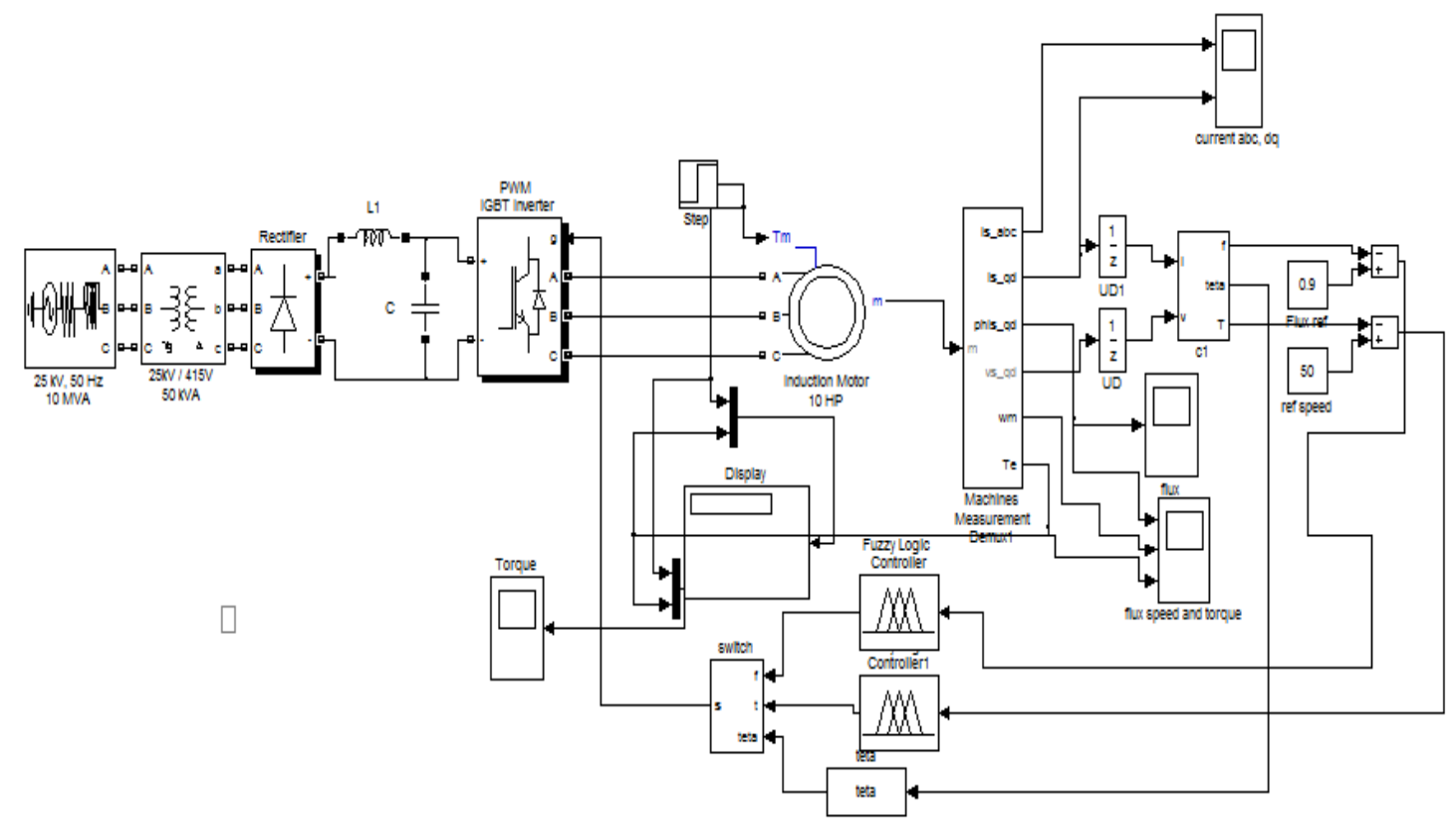

Fig. 7 Simulink model for SVM based DTC with fuzzy logic controllers 
The proposed system is shown in fig. 7. The model includes subsystems for flux and torque calculations and switching vector determinations. Torque control dynamic performance of developed DTC model is evaluated by applying a step change in input of amplitude $20 \mathrm{Nm}$ from $10 \mathrm{Nm}$ after $5 \mathrm{~s}$ while the stator flux reference is maintaied at $1 \mathrm{~Wb}$.
Interesting results are shown in fig. 8 . As shown in fig. 8 the flux and torque pulsations are smaller in the proposed SVM based DTC with fuzzy controllers compared with conventional DTC. Fig. 9 shows the speed response obtained in speed control mode of DTC after introducing a PI controller.

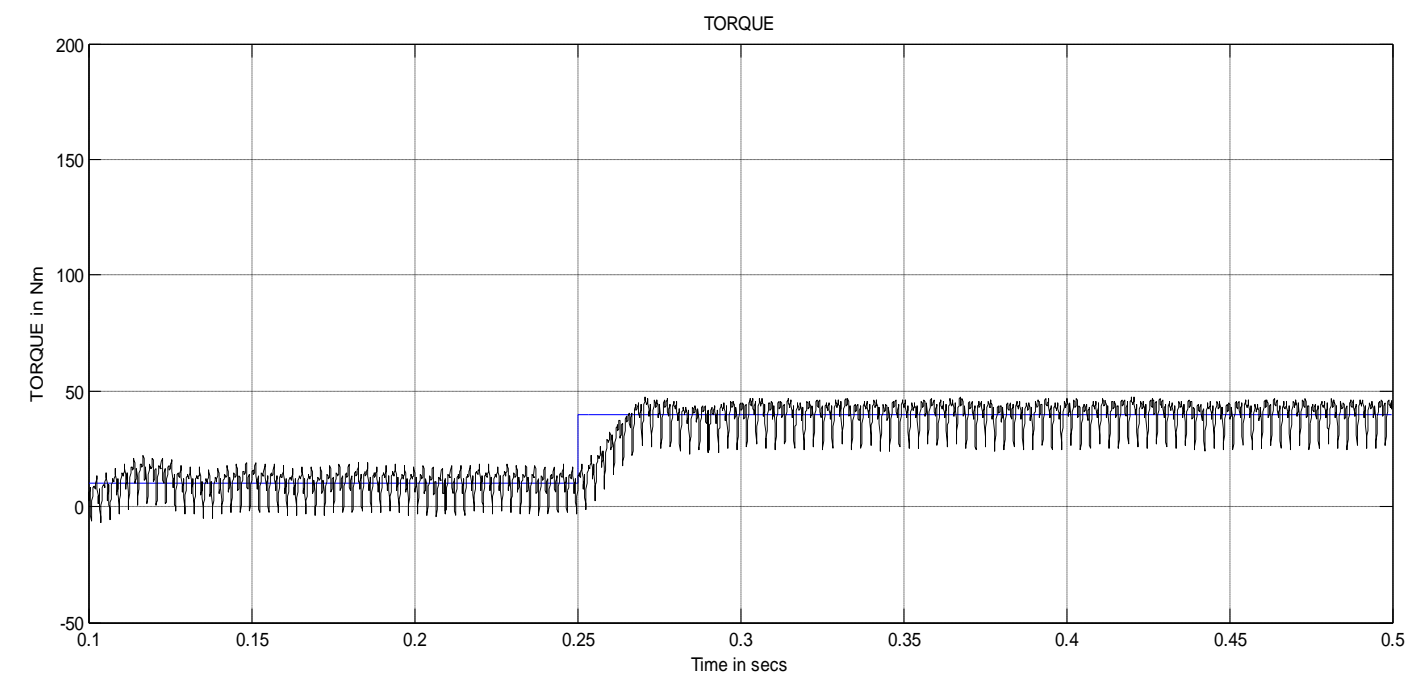

Figure 8 (a) The electromagnetic torque in conventional DTC

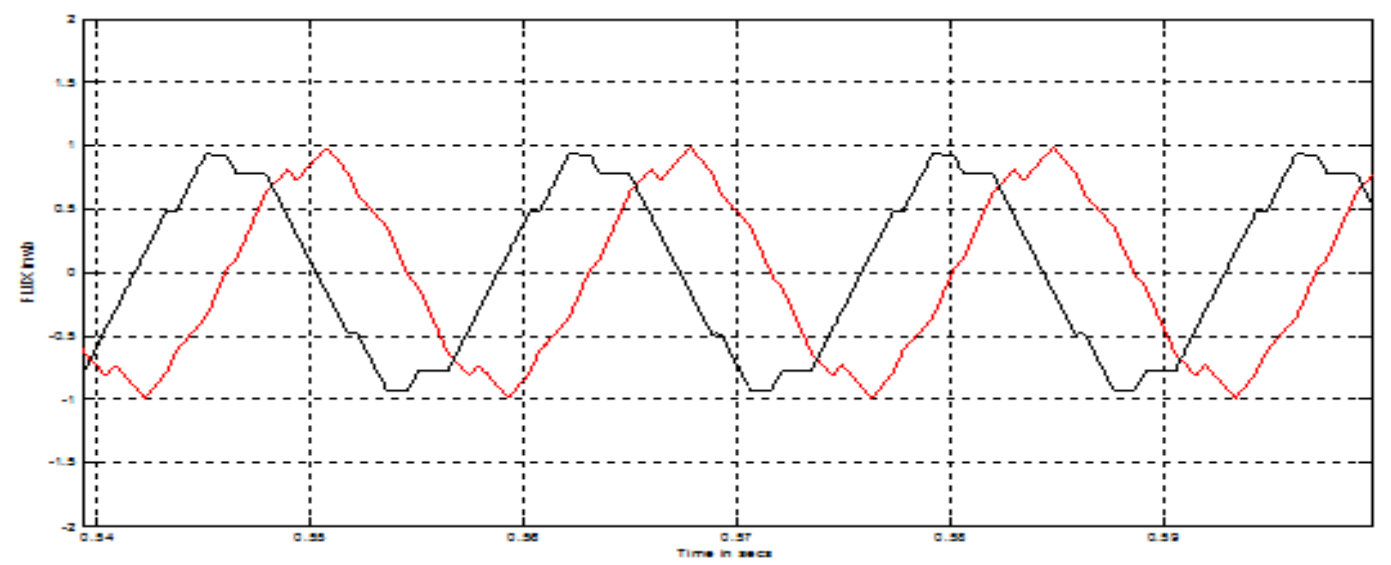

Figure 8 (b) The $d$ and $q$ axes stator fluxes in conventional DTC

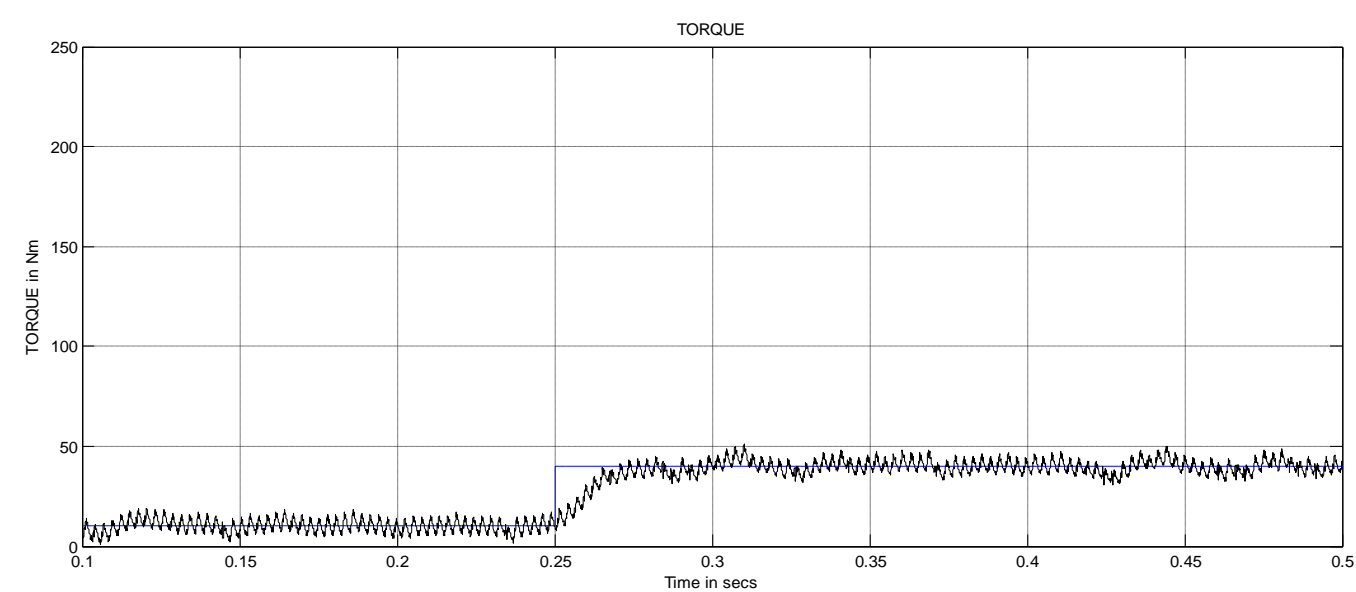

Figure 8 (c) The electromagnetic torque in fuzzy logic based DTC 


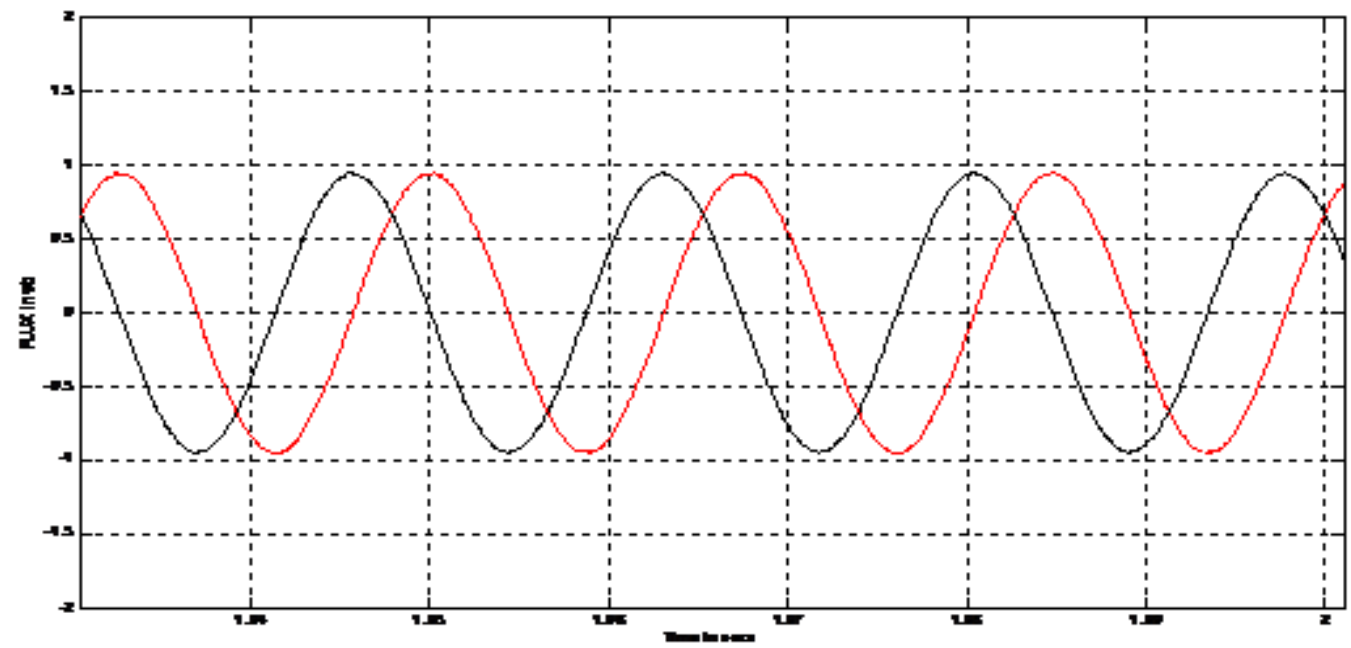

Figure 8 (d) The d and q axes stator fluxes in fuzzy logic based DTC

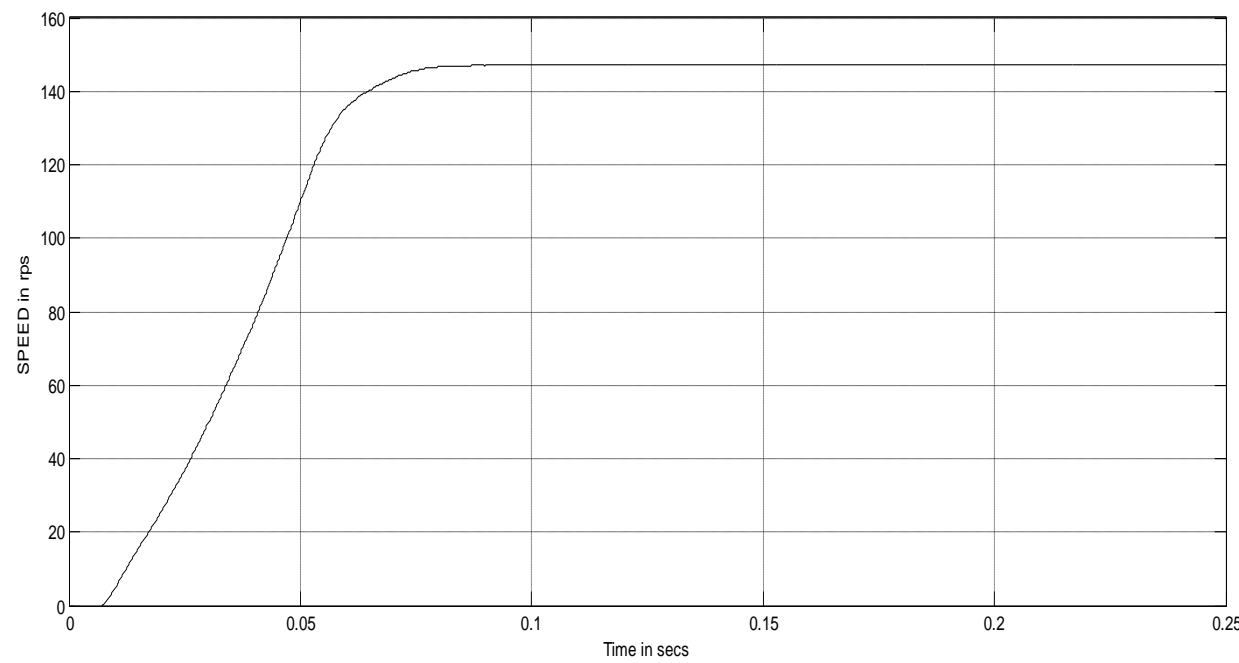

Figure 9. Speed response with PI controller

\section{CONCLUSIONS}

In this paper a new space vector modulation based direct torque control technique with fuzzy logic controllers were proposed. The main focus of this paper is to minimize the torque pulsations in the conventional DTC. The proposed control technique was modeled and simulated in MATLAB/SIMULINK environment. The simulation results proved the superiority of the proposed control technique. i.e. the SVM preserves constant switching frequency and fuzzy logic technique improves the torque control dynamic performance by reducing the torque pulsations.

\section{REFERENCES}

[1] Bose, B.K. (2001). Modern Power Electronics and AC Drives, Englewood Cliffs, NJ: Prentice-Hall.

[2] Krishnan, R. (2002). Electric Motor Drives - Modeling, Analysis, and Control, Prentice-Hall of India.
[3] Finch, J.W.; Giaouris, D. (2008). Controlled AC Electrical drives, IEEE Trans. on Industrial Electronics, Vol. 55, 481-491.

[4] Takahashi,I.; Noguchi,T. (1986). A new quick response and high efficiency control strategy of an induction motor, IEEE Trans. on Industry Applications, Vol.1A$22,820-827$.

[5] Buja, G.S.; Kazmierkowski, M.P. (2004). Direct Torque control of PWM Inverter-Fed AC Motors - A Survey, IEEE Trans. on Industrial Electronics, Vol. 51, 744-757.

[6] Abdul Wahab, H.F.; Sanusi, H. (2008). Simulink Model of Direct Torque Control of Induction Machine, American Journal of Applied Sciences, Vol.5, 10831090.

[7] Ryu, J.H.; Lee K.W.; Lee, J.S. (2006). A unified flux and torque control method for DTC based induction motor drives, IEEE Trans. on Power Electronics, Vol. 21, 234242 
[8] Mengoni M.; Zarri, L.; Tani, M.; Serra, G.; Casadei, D. (2008). Stator flux vector control of Induction Motor drive in the field weakening region, IEEE Trans. on Power Electronics, Vol. 23, 941-949.

[9] Srinivasa Kishore Babu,Y.; Tulasi Ram Das, G. (2010). Improvement in Direct Torque Control of Induction Motor using fuzzy logic duty ratio controller, ARPN Journal of Engineering and Applied Sciences, Vol.5, No.4, 68-73.

[10] Jagadish H. Pujar; Kodad,S.F. (2009). AI based Direct Torque Fuzzy Control of AC Drive, International Journal of Electronic Engineering Research, Vol.1, No.3, 233244.

[11] Toufouti, R.; Meziane, S.; Benalla, H. (2007). Direct Torque Control for Induction Motor using intelligent techniques, Journal of Theoretical and Applied Information Technology, 35-44.
[12] Idris, N.R.N.; Yatim, A.H.M. (2004). Direct Torque control of Induction machines with constant switching frequency and reduced torque ripple, IEEE Trans. on Industrial Electronics, Vol. 51, 758-767.

[13] Habetler, T.G.; Profumo, F.; Astorelli, M.; Tolbert, L.M. (1992). Direct Torque control of induction motor using space vector modulation, IEEE Trans. on Industry Applications, Vol. 28, 1045-1053.

[14] Zhifeng, Z.; Renyuan, T.; Baodong, B.; and Dexin, X. (2010). Novel Direct Torque Control Based on Space Vector Modulation with Adaptive Stator Flux Observer for Induction Motors, IEEE Trans. on Magnetics, Vol.46, 3133- 3137.

[15] Sahoo, S.K.; Das, G.K.R.; Subrahmanyam, V. (2008). VLSI design approach to high - performance direct torque control of induction motor drives, World Journal of Modelling and Simulation, Vol.4, 269-276.

[16] ABB Suomessa, http://www.abb.fi/vsd/index.htm 